\title{
Cholecystoduodenal Fistula: A Case Report Omer Engin
}

\section{Abstract}

Fistula between gall bladder and gastrointestinal tractus occurs anywhere for example stomach, duodenum, and colon. Results of inflammatory reaction adhesion may be occur and between two organs and gall stone's pressure may be contribute this process. After that fistula occurs. Fistula's size is ranging from a few millimeters to centimeters. Malignant tumors can cause fistula too $[1,2]$.

Keywords: Cholecystitis; Fistula; Cholecystoduodenal; Acute abdomen; Icter; Bilirubin; Colon
Department of Surgery, Buca Seyfi Demirsoy State Hospital, Izmir, Turkey

\section{Corresponding author: Omer Engin}

झ omerengin@hotmail.com

Department of Surgery, Buca Seyfi Demirsoy State Hospital, Izmir, Turkey.

Tel: +902324525252

Citation: Engin O. Cholecystoduodenal Fistula: A Case Report. J Univer Surg. 2016, $5: 1$.

Our case is of 42 years old female. She was applied to us for cholecystectomy. Contracted chronic cholecystitis with gallstone is diagnosed in ultrasonographic examination. Laparoscopic cholecystectomy was intended for the patient, this was converted to open cholecystectomy because of the dense adhesions between gall bladder and duodenum. Very dense adhesion is diagnosed between gall bladder and duodenum. For prevent injury of duodenum, wall of the gall bladder was incised on the duodenum so duodenum was separated from the gall bladder. After that fistula was visualized (Figure 1). Cholecystectomy was done and fistula was sutured. Omentoplasty was applied on the sutured fistula's region. Pathologic examination result was benign.

\section{Conclusions}

Preoperative diagnosis of the fistula may be impossible. Fistula is very important and complicated situations. Such cases may have very dense adhesions. Cholecystectomy and fistulotomy and repair of fistula must be done [1-3].

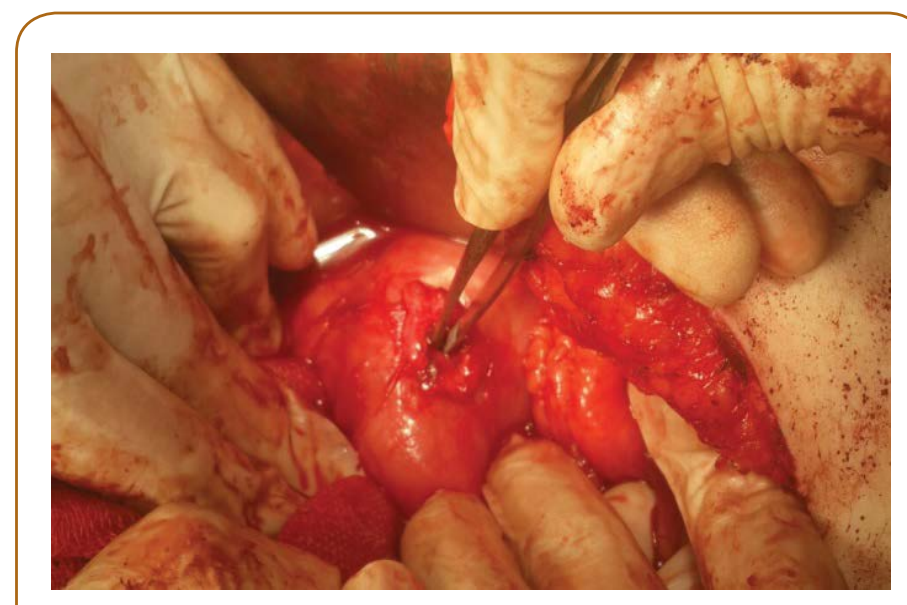

Figure 1 Visuals of fistulas. 


\section{References}

1 Yakan S, Engin O, Tekeli T, Calik B, Deneçli AG, et al. (2010) Gallstone ileus as an unexpected complication of cholelithiasis: diagnostic difficulties and treatment. Ulus Travma Acil Cerrahi Derg 16: 344348.
2 Khosla MS, Nadir A, Ravi J, Chuang KY (2016) invasive gallbladder cancer with a cholecystoduodenal fistula allowing direct gallbladder biopsy through egd. The American Journal of Gastroenterology 111: 1228-1228.

3 Hill BC, Burke LH, Ertl CW (2013) Cholecystoduodenal fistula in a patient post-Roux-en-Y gastric bypass. BMJ case reports. 